\section{Representações sobre dengue, seu vetor e ações de controle por moradores do Município de São Sebastião, Litoral Norte do Estado de São Paulo, Brasil}

\author{
Social representations concerning dengue, dengue \\ vectors, and control activities among residents \\ of São Sebastião on the northern coast of \\ São Paulo State, Brazil
}

\author{
1 Instituto de Pesquisa do \\ Discurso do Sujeito Coletivo, \\ São Paulo, Brasil. \\ 2 Superintendência de \\ Controle de Endemias, \\ São Paulo, Brasil. \\ 3 Faculdade de Saúde \\ Pública, Universidade de \\ São Paulo, São Paulo, Brasil. \\ Correspondência \\ A. M. C. Lefèvre \\ Instituto de Pesquisa do \\ Discurso do Sujeito Coletivo. \\ Rua Cristiano Viana 937, \\ São Paulo, SP \\ 05411-001, Brasil. \\ ana@ipdsc.com.br
}

\begin{abstract}
This study sought to identify people's knowledge on dengue and its vector biology, aimed at promoting a communications channel between technical and lay reasoning in order to foster community involvement in dengue and dengue vector control activities. A survey was conducted in an Aedes aegypti-infested area with dengue transmission in São Sebastião on the northern coast of São Paulo State, Brazil. One hundred interviews were held, with five open questions on topics related to dengue and vector control. Collective Subject Discourse methodology was used in the analysis. People were not able to properly identify the kinds of accumulated water sources that serve as breeding places for mosquitoes and were unaware of the egg phase in vector development. There was inadequate awareness of vector biology and a need for greater governmentcommunity integration. Educational activities should incorporate the study results as insight for improving the social efficiency and efficacy of joint actions to fight dengue and control the mosquito vector.
\end{abstract}

Dengue; Health Promotion; Vector Control
Ana Maria Cavalcanti Lefèvre 1

Andressa Francisca Ribeiro 2

Gisela Rita de Alvarenga Monteiro Marques 2

Lígia Leandro Nunes Serpa 2

Fernando Lefèvre 3

\section{Introdução}

A sociedade moderna tem convivido com processos crescentes e concomitantes de urbanização acelerada, poluição, degradação ambiental, deficiências de infra-estrutura, saneamento e educação. Todos esses fatores podem contribuir para o surgimento de doenças transmitidas por vetores que geram conseqüências indesejáveis para a qualidade de vida da população 1 .

Entre as doenças vetoradas, a dengue merece atenção porque, mesmo na forma clássica, gera transtornos físicos para a população, além de grandes gastos de recursos financeiros na tentativa de controle. Quanto à forma grave, há o risco e a ocorrência de óbitos, gerando altos custos para o setor de saúde 2 . Por sua vez, em saúde pública, pouco ou quase nada se consegue sem a participação de todos, e essa participação no caso da dengue refere-se à incorporação do conhecimento sobre a doença não somente pela população em geral, mas também pelos diversos setores da sociedade responsáveis pela produção de descartáveis que podem tornar-se criadouros do mosquito ${ }^{3}$. Por isso, toda a sociedade deve ser engajada no controle da dengue, não somente o serviço público.

Atualmente podem ser notadas mudanças na conduta das indústrias em geral por meio da implementação da ISO 14000, incentivo à política dos três "R" (reduzir, reutilizar e reciclar) e implementação de atividades educativas para popula- 
ções que residem próximo a essas indústrias. No entanto, a consciência preventiva e a incorporação dos conhecimentos ocorrerão somente a partir do momento em que as pessoas, voluntariamente e com plena compreensão, aceitarem, em face de seus contextos de vida, os objetivos do programa.

Para entender o processo pelo qual as pessoas constroem o conhecimento e dão significado à prevenção da dengue, partimos do entendimento de que a vida cotidiana apresenta-se como uma realidade interpretada pelos homens, para os quais é subjetivamente dotada de sentido apenas na medida em que forma um mundo coerente 4 .

Estudos realizados por Chiaravalloti Neto et al. ${ }^{5}$ e Chiaravalloti et al. ${ }^{6}$ demonstraram que, isoladamente, os conhecimentos sobre a dengue e os vetores foram incorporados pela população, mas não corresponderam necessariamente a uma mudança de hábitos e conseqüentemente a uma redução do número de criadouros a ponto de evitar a transmissão da dengue.

Possivelmente isso se deva à natureza formal e "externa" desse conhecimento adquirido, bem como a seu caráter fragmentário ou precariamente organizado, o que configura o conflito comunicativo que Lefèvre \& Lefèvre 7 postulam entre a lógica sanitária e a lógica do senso comum.

São Sebastião, município do Estado de São Paulo, localizado próximo a outros centros urbanos maiores que foram infestados anteriormente, teve seu primeiro registro da presença de Aedes aegypti em 1996. Embora alvo sistemático de atividades de vigilância e controle, o município apresentou infestação domiciliar a partir do ano 2000. Em um estudo epidemiológico realizado na cidade 8 , pôde-se identificar que houve notificações de casos autóctones da doença a partir de 2001, estendendo-se até 2004, com circulação simultânea de três sorotipos virais (DEN-1, 2 e 3). Tal perfil epidemiológico pode favorecer a ocorrência de casos de dengue hemorrágica.

Há muitos anos, o componente educativo tem sido incorporado ao Programa de Controle de $A e$ des aegypti, na região do litoral norte do Estado de São Paulo, entretanto, até o momento, parece não ter provocado mudanças no comportamento da população, considerando-se a freqüência de criadouros positivos em área infestada. De acordo com Arduíno \& Kita 9, em São Sebastião, do total dos recipientes que foram encontrados com larvas de Ae. aegypti, 55\% destes poderiam ter sido eliminados pela coleta seletiva de lixo disponível no município.

Tais dados apontam para a necessidade de se estudar a problemática educativa a fim de iden- tificar, com mais precisão e detalhe, o conhecimento da população, seus eventuais lapsos, seu grau de organicidade, com vistas ao enfrentamento da defasagem entre a informação e a prática, o que poderá contribuir para o incremento da desejável e necessária participação popular no controle do vetor no local de estudo.

\section{Metodologia}

\section{$\underline{\text { Região de estudo }}$}

Localizado no litoral norte do Estado de São Paulo, o Município de São Sebastião situa-se entre as coordenadas latitude Sul 23021'20" e longitude Oeste $45^{\circ} 21^{\prime} 00^{\prime \prime}$, a $220 \mathrm{Km}$ da capital paulista. Sua superfície territorial é de $520 \mathrm{Km}^{2}$, sendo aproximadamente $300 \mathrm{Km}^{2}$ cobertos por Mata Atlântica. Segundo o censo demográfico do Instituto Brasileiro de Geografia e Estatística (http:/ /www. ibge.gov.br, acessado em 03/Jan/2006), a população estimada no ano de 2005, nesse município, é de 73.167 habitantes. Atualmente, sua área urbana extrapola os limites das planícies, invadindo as montanhas costeiras. Esse processo intenso e desordenado de ocupação, exercido pelo crescimento da população urbana e, principalmente, da flutuante, colabora para o agravo da prestação dos serviços de saneamento básico como: abastecimento de água, rede coletora de esgoto, limpeza urbana e coleta de lixo.

\section{Planejamento da amostragem}

Adotou-se amostragem por conglomerados em dois estágios: quarteirões e depois edificações. Foi selecionada uma área considerada de antiga infestação por Ae. aegypti e com transmissão de dengue nos últimos cinco anos, que atualmente apresenta 502 quadras e 17.535 imóveis 10. Tal região reúne os bairros que fazem limite com o Município de Caraguatatuba, estendendo-se até o bairro de Barequeçaba. A população dessa área representa aproximadamente $60 \%$ da população total do município, sendo $50 \%$ de residências fixas, $35 \%$ de imóveis de veraneio e o restante de imóveis comerciais 10. O tamanho da amostra foi de cem imóveis a serem pesquisados; a partir daí determinou-se o número de quarteirões que compuseram a amostra. A escolha das quadras foi realizada segundo método de amostragem sistemática, que consistiu em definir primeiramente a quadra inicial por meio da tabela de números aleatórios e as demais, somando-se um intervalo amostral. Esse procedimento está baseado no plano de amostragem utilizado na avaliação de densidade larvária (índice de Breteau) 
do Programa de Controle de Dengue e Febre Amarela 11.

Os domicílios nos quais se deram as entrevistas foram definidos por meio de sorteio numérico. Para tanto, considerou-se o número de imóveis por quadra, informação disponível em virtude das atividades de controle de dengue realizadas pelo município. Para a localização exata do imóvel no quarteirão, o número do imóvel sorteado era localizado após o posicionamento do entrevistador na esquina mais ao norte da quadra amostrada. Em seguida, ele iniciava a contagem das casas em sentido horário até atingir o número sorteado. Quando havia recusa de entrevista ou ausência do morador, consideravase o imóvel seguinte.

\section{A entrevista e características da população}

Definiu-se como critério importante entrevistar indivíduos maiores de 21 anos e com residência fixa no imóvel por se caracterizarem responsáveis por este.

Antes do início da entrevista, realizava-se a leitura do Termo de Consentimento Livre e Esclarecido para o entendimento dos objetivos da pesquisa e a assinatura dos entrevistados. Em seguida, os depoimentos eram gravados em fita magnética. As entrevistas continham cinco questões abertas que abordavam aspectos de interesse da pesquisa. Por tratar-se de trabalho com seres humanos utilizando-se de seus discursos, o Termo de Consentimento Livre e Esclarecido foi submetido e aprovado pelo Comitê de Ética em Pesquisa da Universidade de Taubaté.

\section{Discurso do sujeito coletivo: princípios} da metodologia

A teoria da Representação Social pode ser esquematicamente definida como o conhecimento associado à vida cotidiana das pessoas, que é elaborado em sociedade e que tem por função servir de instrumento para que os atores sociais possam interpretar, pensar e agir sobre a realidade. Tal conhecimento é estruturado tanto individualmente quanto socialmente e transmitido desde o nascimento, incorporando valores, motivações e normas de nosso ambiente social 12 .

Tendo como fundamento a teoria da Representação Social e seus pressupostos sociológicos, a proposta do Discurso do Sujeito Coletivo 13,14 , associada a seu programa de computador, o QualiQuantiSoft (Instituto de Pesquisas do Discurso do Sujeito Coletivo; http://www.ipdsc. com.br, acessado em Nov/2005), consiste basicamente em uma técnica quali-quantitativa de análise do material verbal coletado de respostas a questões abertas, em pesquisas sociais empíricas, extraindo-se de cada um dos depoimentos as idéias centrais e ancoragens e as suas correspondentes expressões-chave. Com as idéias centrais/ancoragens e expressões-chave semelhantes, compõe-se um ou vários discursos-síntese, redigidos na primeira pessoa do singular, que são os Discursos do Sujeito Coletivo (DSC).

As expressões-chave são trechos do discurso que devem ser destacados do material verbal de cada depoimento, pois revelam a essência do conteúdo do discurso.

A idéia central é um nome ou expressão lingüística que descreve, de maneira mais sintética e precisa possível, o sentido de cada um dos discursos analisados e de cada conjunto homogêneo de expressões-chave, que vai dar origem ao DSC. Algumas expressões-chave remetem não apenas a uma idéia central correspondente, mas também, e explicitamente, a uma afirmação que denominamos ancoragem, que é a expressão de uma dada teoria ou ideologia que o autor do discurso professa e que está embutida no seu discurso como se fosse uma afirmação qualquer. Na metodologia do DSC, considera-se que existem ancoragens apenas quando estão presentes, no material verbal, marcas discursivas explícitas dessas afirmações genéricas.

Ainda de acordo com essa metodologia, as dimensões qualitativa e quantitativa estão intimamente associadas, na medida em que cada DSC - entidade discursiva/qualitativa - é composto com a contribuição do material das expressões-chave de distintos depoimentos, o que confere - quantitativamente - um peso específico para cada DSC, revelando diferentes graus de compartilhamento de uma idéia pela população.

\section{Resultados e discussão}

A Tabela 1 contempla o perfil dos entrevistados. Os participantes desta pesquisa eram moradores de 13 bairros do município em questão. Por meio do método de amostragem, $49 \%$ dos indivíduos estavam localizados na região Sul da área trabalhada, que, coincidentemente, registrou elevadas incidências de dengue entre os anos de 2000 a 2004. Durante o processo epidêmico, observou-se que a área acometida apresentava maior freqüência de casos porque possuía como características a elevada densidade populacional, intenso fluxo turístico e comercial, além de serem áreas contíguas 8 .

Em relação ao sexo, observa-se que em sua maioria os entrevistados eram mulheres (69\%). A faixa etária predominante (56\%) foi de 21 a 40 
Perfil dos entrevistados. Município de São Sebastião, São Paulo, Brasil.

\begin{tabular}{|c|c|c|c|c|c|c|c|c|c|c|c|c|c|c|}
\hline & $\begin{array}{c}\text { Arras- } \\
\text { tão }\end{array}$ & $\begin{array}{c}\text { Reserva } \\
\text { Moulin }\end{array}$ & $\begin{array}{c}\text { Ense- } \\
\text { ada }\end{array}$ & $\begin{array}{c}\text { Pontal } \\
\text { da } \\
\text { Cruz }\end{array}$ & $\begin{array}{l}\text { São } \\
\text { Fran- } \\
\text { cisco }\end{array}$ & Centro & $\begin{array}{c}\text { Bairro } \\
\text { Cigar- } \\
\text { ras }\end{array}$ & $\begin{array}{c}\text { Canto } \\
\text { do } \\
\text { Mar }\end{array}$ & $\begin{array}{l}\text { Jara- } \\
\text { guá }\end{array}$ & $\begin{array}{l}\text { Porto } \\
\text { Grande }\end{array}$ & $\begin{array}{c}\text { Portal } \\
\text { da } \\
\text { Olaria }\end{array}$ & $\begin{array}{c}\text { Morro } \\
\text { do } \\
\text { Abrigo }\end{array}$ & $\begin{array}{c}\text { Praia } \\
\text { Deserta }\end{array}$ & Total \\
\hline \multicolumn{15}{|l|}{ Sexo } \\
\hline Masculino & - & - & 5 & 5 & 5 & 4 & 4 & 3 & 1 & 1 & 1 & 1 & 1 & 31 \\
\hline Feminino & 3 & 1 & 12 & 11 & 9 & 11 & 1 & 6 & - & 8 & 4 & 2 & 1 & 69 \\
\hline \multicolumn{15}{|l|}{ Idade (anos) } \\
\hline $20-40$ & 2 & 1 & 7 & 9 & 7 & 8 & 3 & 6 & 1 & 4 & 5 & 1 & 2 & 56 \\
\hline $41-60$ & - & - & 5 & 3 & 7 & 6 & 1 & 3 & - & 3 & - & 1 & - & 29 \\
\hline 61 ou + & 1 & - & 5 & 4 & - & 1 & 1 & - & - & 2 & - & 1 & - & 15 \\
\hline \multicolumn{15}{|l|}{ Escolaridade } \\
\hline Nenhuma & 1 & - & 1 & - & - & - & - & - & - & - & - & - & - & 2 \\
\hline 1o grau incompleto & - & 1 & 10 & 2 & 6 & 2 & - & 6 & 1 & 2 & 2 & 2 & - & 34 \\
\hline 1ㅇ grau completo & 2 & - & - & 2 & - & 2 & - & - & - & 1 & - & - & - & 7 \\
\hline 2o grau incompleto & - & - & - & 2 & 2 & 1 & - & 1 & - & 1 & - & - & - & 7 \\
\hline 2o grau completo & - & - & 6 & 9 & 2 & 6 & - & 2 & - & 1 & 3 & 1 & - & 35 \\
\hline 3o grau incompleto & - & - & - & - & 1 & 1 & 4 & - & - & 2 & - & - & 1 & 5 \\
\hline 3o grau completo & - & - & - & 1 & 3 & 3 & 1 & - & - & 2 & - & - & 1 & 10 \\
\hline
\end{tabular}

anos de idade, com 29 indivíduos entre 41 a 60 anos e 15 com 60 anos ou mais.

A distribuição da escolaridade revelou que $64 \%$ da população abordada apresentou formação escolar acima do primeiro grau completo. Entre os $36 \%$ restantes destaca-se que apenas dois indivíduos não tinham qualquer instrução.

Os resultados quali-quantitativos do DSC serão mostrados por questão enunciada, com as respectivas idéias centrais e a proporção obtida para cada uma delas. Apenas o DSC da idéia central mais freqüente, portanto, a mais compartilhada, será aqui apresentado. No entanto, os comentários referem-se a todos os discursos encontrados.

\section{Representações sociais sobre a gravidade da doença}

Na Tabela 2, estão as idéias centrais referentes à pergunta 1 ("Você já ouviu falar em dengue? É uma doença perigosa ou não?”).

\section{- DSC da idéia central A}

“É perigosa! Nossa, judia muito! É perigosa porque causa doenças. Essa doença, o dengue, eu sei que é uma doença perigosa. Se não cuidar a tempo pode levar à morte. Segundo o que fiquei sabendo, em vista do que tem sido divulgado na notícia e na televisão, em vista do que a gente conhece, eu ouvi que pode até matar, se a pessoa pegar a dengue ela pode até morrer; diz que chega até matar se não levar a tempo pra medicar, se não for diagnosticado no primeiro momento. As pessoas, elas estão cientes, mas só que mesmo assim abusam um pouco".

\section{- Comentários}

Levando-se em conta as várias idéias encontradas sobre este subtema, observa-se que há uma percepção graduada do perigo causado pela doença. Segundo os entrevistados, o perigo máximo é a morte, imediatamente abaixo do qual vem o perigo da dor e depois o prejuízo causado com os dias de inatividade, além do fato de a dengue ser vista como mais perigosa para crianças e idosos.

Salienta-se que $17,05 \%$ das respostas relacionam o perigo representado pela dengue a uma experiência próxima: afinal trata-se de município com casos autóctones da doença nos últimos anos 8 . Em 13\% das respostas, revelam-se idéias de que é preciso fazer alguma coisa.

Excluindo-se um número muito pequeno de respostas $(2,31 \%)$ que referem não saber se a doença é perigosa, observa-se que a população estudada apresenta um grau de informação bastante amplo sobre a enfermidade e sua gravidade. 
Pergunta 1: "Você já ouviu falar em dengue? É uma doença perigosa ou não?".

\begin{tabular}{lr}
\hline Idéias centrais & Respostas (\%) \\
\hline A) Sim, porque pode levar a pessoa à morte. & 22,48 \\
B) Acha que é perigosa por ter visto, ouvido ou vivido a experiência. & 17,05 \\
C) Sim, porque produz sintomas graves causando danos à saúde. & 14,73 \\
D) Sim, dependendo do tipo. & 10,85 \\
E) É perigosa, e é preciso controlar o meio ambiente e conscientizar as pessoas. & 10,85 \\
F) Sim, porque é contagiosa, transmissível, podendo causar epidemias. & 8,53 \\
G) Sim, quando a pessoa tem dengue mais de uma vez. & 5,43 \\
H) É mais perigosa para crianças e idosos. & 3,88 \\
l) Sim, e a pessoa precisa ter cuidados. & 2,33 \\
J) Não sabe ou não tem certeza se é perigosa. & 2,33 \\
K) Sim, é perigosa. & 1,55 \\
Total (11 idéias centrais) & 100,00 \\
\hline
\end{tabular}

Representações sociais sobre a biologia do vetor

As idéias centrais referentes à pergunta 2 ("Você sabe como o mosquito da dengue se cria?") são apresentadas na Tabela 3.

\section{- DSC da idéia central A}

“Eu ouço dizer que é nas águas. Através de água parada, do acúmulo de água nos pneus, garrafas, o acúmulo de água parada da chuva ou da lavagem do quintal faz com que prolifere o mosquito do dengue. Dizem que é uns bichinho pretinho, né? Assim eu ouvi falar, eu mesmo não cheguei a ver. O mosquito eles cria em água parada. Eles avisa muito pra não deixar água parada, sempre usar areia nos pratinhos do vaso, pra tomar cuidado. Ele cria em garrafas aberta, em plástico, em lata, porque enche de água; em vaso de flor, com aqueles pratinho embaixo, se deixar sem colocar uma areia ela vai criando o mosquito; nos pneu com água de chuva, e sacolas de plástico também. Tem várias coisas que fica jogada espalhada no quintal e junta, vai ficando ali aí chove e aquela água vai juntando os mosquito do dengue".

\section{- Comentários}

Os discursos obtidos nesta questão parecem revelar uma série de problemas com as informações relativas à "criação" do mosquito. A água limpa, suja, acumulada, empoçada ou de chuva parece, para a população estudada, estar associada à criação do mosquito, o que revela que a população não está conseguindo discriminar adequadamente que tipo ou modalidade de coleção de água seria o mais apropriado para a criação do mosquito, como nos mostram as idéias centrais A, B ou D.

Outro aspecto importante é o problema da larva e do ovo. Dentre as respostas, $13,21 \%$ dos pesquisados revelam desconhecimento explícito da fase de ovo no desenvolvimento do mosquito, como nos mostra a idéia central C. É de se supor que poucos estejam a par da aderência do ovo à parede dos recipientes e conseqüentemente do transporte passivo do ovo. Observa-se, portanto, que é quase inexistente a percepção da população em relação aos recipientes potenciais, ou seja, aqueles que por ocasião da vistoria não apresentam água, mas que podem retê-la a qualquer momento.

\section{Representações sociais sobre os serviços de saúde e fatores que impedem o controle do vetor}

A Tabela 4 mostra as idéias centrais sobre a pergunta 3("A SUCEN e a prefeitura municipal estão tentando há alguns anos controlar a dengue. $\mathrm{Na}$ sua opinião, eles estão conseguindo fazer isso ou não? (...) Por quê?").

\section{- DSC da idéia central A}

“Ah, provavelmente estão, porque senão o índice de mosquitos e de doenças estaria bem alastrado, né? Pelo menos no meu bairro eu acho que sim, pra cá eu nunca vi casos. Então quer dizer que tinha uma fiscalização grande aqui. E eles andam sempre aqui e não têm mais encontrado os mos- 
Pergunta 2: "Você sabe como o mosquito do dengue se cria?".

\begin{tabular}{lr}
\hline Idéias centrais & Respostas (\%) \\
\hline A) O mosquito se cria em água acumulada e/ou parada dentro de recipientes. & 34,91 \\
B) O mosquito se cria em água limpa, parada e/ou dentro de recipientes. & 29,25 \\
C) O mosquito se cria por meio das larvas que são depositadas na água dentro de recipientes. & 13,21 \\
D) O mosquito se cria em água suja acumulada dentro de recipientes. & 7,55 \\
E) O mosquito se cria por meio de ovos que são colocados na água dentro de recipientes. & 5,66 \\
F) Não sabe. & 5,66 \\
G) O mosquito se cria em água parada limpa ou suja dentro de recipientes. & 3,77 \\
Total (7 idéias centrais) & 100,00 \\
\hline
\end{tabular}

Tabela 4

Pergunta 3: "A SUCEN e a prefeitura municipal estão tentando há alguns anos controlar a dengue. Na sua opinião, eles estão conseguindo fazer isso ou não? (...) Por quê?".

\begin{tabular}{lc}
\hline Idéias centrais & Respostas (\%) \\
\hline A) Estão conseguindo porque diminuiu o índice de mosquito e o número de doentes. & 29,63 \\
B) Estão conseguindo devido à ação educativa e ao trabalho dos agentes de controle. & 29,63 \\
C) Não, porque precisaria de um trabalho integrado entre Estado, Município e população. & 13,89 \\
D) Estão tentando controlar, mas... & 9,26 \\
E) Não, porque a ação de controle não está sendo eficiente. & 8,73 \\
F) Não porque a população não contribui. & 3,70 \\
G) Não sabe. & 3,70 \\
H) Estão conseguindo porque a população tem colaborado. & 1,85 \\
Total (8 idéias centrais) & 100,00
\end{tabular}

quitos, né? Quando surgiu a epidemia de dengue, você via muita gente falar que tava com dengue, que pegou dengue, e hoje, são poucas as pessoas que falam que teve dengue nos últimos dias ou que está com dengue. Os dados de dengue deu bem menos, porque teve uma época que deu bastante resultado aqui. S. Sebastião, Caraguá, né? Agora, os casos que aparecia é porque vinha de fora, mas aqui era controlado. $O$ ano retrasado aqui teve muita gente que pegou, e muita gente mesmo! Do ano passado pra cá, a gente não escutou falar que alguém teve dengue por aqui. Então acredito que tenha combatido, porque eu não tenho notícia de pessoa internada com dengue recentemente. Pelo menos não está sendo divulgado nada, eu não soube mais de casos de dengue atualmente".

\section{- DSC da idéia central B}

"Acho que sim, porque eu sempre vejo pessoas passando e dando informações. A minha neta estuda tá pequenininha ainda, tá na creche. Algumas pessoas foram fazer uma entrevista na creche pra perguntar pras criança como é que é em casa. E eles responderam que os pais e os avós cuidam bem dos vasos de planta, não deixam água. A equipe responsável pelo combate a dengue tem visitado as casas, dando as instruções de como evitar a proliferação do mosquito, as técnicas desde colocar cloro nos ralos e não deixar água parada. Eu tenho visto alguns carros com fumaça, os profissionais passando, controlando, entregando pozinho, remedinhos que fazem o controle da dengue. Aqui por exemplo, sempre tem passado a rapaziadinha coletando o lixo, olha a piscina, olha se tem água parada e até perturba um pouquinho. Ás vezes vem em horário que a gente ta almoçando, porque não tem horário pra vir. Alguns entram na residência e olham o quintal para ver se tem alguma água parada em alguma coisa, alerta sobre as coisas que gera a dengue, gera o mosquito, eles estão sendo bem cuidadosos. Esse ano já passou 
uma porção de pessoas aqui em casa pra ver como é que está o quintal. A minha casa graças a Deus está tudo bem. Eles estão visitando quase toda semana. De vez em quando eu até indico algumas casa, mostro casa que não tem tapagem na caixa d'água, casa que fica fechada muito tempo e isso a gente tem medo, por que de lá vem pra nossa casa. Tem gente que não abre a porta, não deixa a pessoa entrar, isso é fato. Tem que conscientizar que não podemos deixar a doença proliferar. Assim como a gente não quer que aconteça com a gente, não vai querer com as outras pessoas. Então a gente procura atender as pessoas da melhor maneira quando eles vem nos visitar. Eu estou satisfeita com o trabalho deles e se não tivesse esse trabalho seria bem pior, viu? Eles estão fazendo um bom trabalho na minha opinião".

\section{- Comentários}

A realização de trabalho técnico de controle e de trabalho educativo junto à população; a diminuição visível do número de doentes e de mosquitos, bem como o trabalho integrado entre os órgãos responsáveis pelo controle do vetor e entre a ação do setor público e a ação da população, constituem os principais critérios usados pela população para avaliar, positiva ou negativamente, a ação dos poderes públicos no que toca ao controle da dengue no município de estudo.

Apesar de a maioria (61\%) avaliar positivamente essa ação, temos $26 \%$ da população que a avalia negativamente; $10 \%$ avaliam com reservas (por motivos variados) e $4 \%$ não sabem dizer se está ou não havendo controle da doença.

De qualquer modo, parece importante os poderes públicos manterem um sistema per- manente de informações sobre o andamento da situação, a fim de induzir a participação da população nas ações de controle.

\section{Representações sociais da população sobre a relação entre dengue e o lixo doméstico}

Na Tabela 5 são listadas as idéias centrais sobre a pergunta 4 ("Na sua opinião, a dengue tem alguma coisa a ver com o lixo? Fale um pouco sobre isso").

\section{- DSC da idéia central A}

"Tem, sem dúvida! Principalmente aqui, que chove bastante, aí os lixos ficam todos abertos e os cachorro rasga. Onde fica lixo jogado é que de um jeito ou de outro fica um acúmulo de água, o mosquito bota a larva, aí já era. Os próprios moradores jogam o lixo na beira da vala; se vem chuva, vai ficar empoçando água até no saquinho e ninguém vai vir cuidar disso aí. Se você deixar vasilha, alguma garrafa aberta ou qualquer coisa, vai dar dengue. Porque a água fica parada ali. Onde há sujeira você pode encontrar água e ele vai se reproduzir. Se você não separa latas, vasilhas que possam ficar com água, o mosquito vai procriar, inclusive o problema desses caracóis que tem aparecido é mais ainda, porque, na verdade, se você mata, acaba ficando a casca, e eu já vi várias vezes ela cheia de água. Então provavelmente ela vai ajudar pra proliferar a dengue. Terreno baldio que fica aquelas vasilha de refrigerante, pneu, essas coisas assim que junta água, isso vira um criadouro. Então tudo depende de quem cuida do lixo, de quem põe o lixo na lixeira. O lixo jogado

Pergunta 4: "Na sua opinião, a dengue tem alguma coisa a ver com o lixo? Fale um pouco sobre isso".

\begin{tabular}{lc}
\hline Idéias centrais & Respostas (\%) \\
\hline A) Sim, em recipientes que acumulam água. & 40,18 \\
B) Sim, porque o mosquito da dengue se cria no lixo, na sujeira. & 19,64 \\
C) Sim, porque o lixo ou a sujeira tem criadouros do mosquito. & 12,50 \\
D) Não ou não sabe. & 11,61 \\
E) Não, porque os mosquitos se criam em água limpa. & 5,36 \\
F) Sim, em recipientes que acumulam água limpa. & 4,46 \\
G) Não, porque os mosquitos se criam em água parada. & 3,57 \\
H) Sim, em recipientes que acumulam água suja. & 0,89 \\
l) Não, porque os mosquitos não gostam de lixo. & 0,89 \\
J) Não, porque os mosquitos se criam em água suja. & 0,89 \\
Total (10 idéias centrais) & 100,00
\end{tabular}


no mato vai juntar água que éonde vai causar, né? Trazer os mosquitos, eles vão pôr mais ovinhos e vão ter mais dengue. Se o coletador demora de 2 a 3 dias pra coletar lixo, daí pode dar problema. Ao contrário, se o caminhão de lixo passa cotidianamente eu penso que não".

\section{- Comentários}

Nota-se que a grande maioria dos entrevistados (78\%) estabelece uma relação positiva entre lixo e dengue. Observa-se expressiva presença nos discursos de uma associação positiva do lixo com a doença no que diz respeito ao recipiente, ou seja, o criadouro do mosquito. Tais dados sugerem a existência de conhecimento entre a doença e o saneamento do meio.

Santos 15 relatou que os recipientes provenientes do lixo doméstico normalmente apresentam menor tamanho, possibilitando, por um lado, rápido acúmulo de água de chuva e, por outro lado, rápida evaporação de água acumulada, o que pode aumentar o risco de contrair outras doenças além da dengue.

Os resultados do presente estudo indicam a necessidade de demonstrar para a população a importância do acondicionamento do lixo, pois, quando inadequado ou ausente, pode favorecer a ocorrência de dengue.

Representações sociais da população sobre a participação popular e responsabilidade no controle do mosquito da dengue

As idéias centrais referentes à pergunta 5 ("Você acha que a população poderia colaborar mais no controle da dengue?”) são apresentadas na Tabela 6.

\section{- DSC da idéia central A}

"Com certeza, tampando as caixas d'água, fazendo suas limpeza de quintal. Poderiam colaborar muito mais, tanto na população daqui, quando da cidade, como os turistas, né? Que tem casa aqui e deixa fechada, podia deixar com algum responsável. Muitas casas a gente vê que eles deixam a casa trancada e simplesmente saem, vão para as suas cidades. Eles não tão nem aí: ó tudo esses terreno aí, você pode ver, tá tudo cheio de água, poças de água, entra e repara: eles não tão nem ligando, se a dengue não pega eles não tem problema nenhum. Eles não se preocupam com isso, e a gente que se ferra. Acho que não é só informação, viu? Enquanto as pessoas não sentirem na pele o problema, ficam achando que não vai acontecer com ele, acontece com o vizinho, mas comigo não acontece, né? Eu acho que as pessoas têm que se chocar mais com a situação. Com certeza têm famílias que cuidam muito bem desse lado, e existem famílias que não estão nem aí pra isso. Isso a gente vê no nosso dia-a-dia. Existem vizinhos que cuidam muito bem e outros deixam tudo aberto e é aí é onde se dá o foco da doença, às vezes do nosso lado, né? Eles dizem: é da prefeitura? Que se dane! Eu acho que a população é muito sossegada, muito tranqüila, sabe? Tipo assim: tem um caso de dengue na família, aí a pessoa começa a se preocupar. Só que se não acontece na família, eles não se preocupam! Entendeu? A população não se ajuda né? Eu já vi casos de pessoas que tiveram mais de duas vezes a dengue, em casa ela tem muita quantidade de planta, e que mesmo assim ela não tomou conhecimento da gravidade da doença. Então ela teve a doença e ela não conseguiu administrar isso dentro da casa dela, acho que não conscientizou; não adianta eu cuidar e o vizinho não cuidar, porque o mosquito que se criar ali na casa dele pode atingir a minha também. Se todos fizessem como eu faço, eu acho que não existia a dengue porque ela não tinha como criar.

O brasileiro no geral é muito mal educado: joga o lixo, aí joga lá uma vasilhinha, que choveu e encheu de água: aí já é um lugarzinho pra ele ta colocando os ovinhos dele. Então se cada um fizesse sua parte essas coisa não estaria acontecendo. Eu já faço. Porque eu já passei por isso e eu sei como é que é: fica um pouco de medo, né?".

\section{- Comentários}

Pode-se observar que o DSC mais freqüente, ou seja, o mais compartilhado entre os entrevistados é aquele segundo o qual a população poderia colaborar mais no controle da dengue e do vetor, mas que não o faz porque "não está nem aî". A falta de colaboração da população também aparece em outros discursos.

A contradição entre discurso e práticas oficiais, tal como revelada pelo anteriormente citado estudo conduzido por Chiaravalloti et al. 6 , pode estar provocando o desinteresse da comunidade no trabalho preventivo.

\section{Conclusão}

Da análise qualitativa e quantitativa dos discursos presentes na pesquisa em tela, algumas grandes linhas de análise podem ser desenvolvidas.

O conhecimento sobre os vários aspectos da dengue revelado pelos entrevistados, como é característico das representações sociais sobre temas técnicos ou científicos 16 , revela-se:

a) incompleto è̀s vezes equivocado, notadamente, como se assinalou, no que toca à relação entre 
Pergunta 5: "Você acha que a população poderia colaborar mais no controle da dengue?".

\begin{tabular}{lc}
\hline Idéias centrais & Respostas (\%) \\
\hline A) Sim, mas é preciso bem mais colaboração: o povo não está nem aí... & 31,06 \\
B) Sim, não deixando recipientes com água acumulada. & 20,69 \\
C) Sim, realizando ações específicas de controle do meio. & 19,83 \\
D) Sim, assumindo a responsabilidade e a consciência que lhe compete como cidadão. & 10,34 \\
E) Sim, realizando coleta seletiva de lixo. & 6,03 \\
F) Sim, seguindo orientações e informações fornecidas pelos órgãos competentes. & 4,31 \\
G) Sim, mas autoridades precisam atuar e colaborar mais. & 4,31 \\
H) Sim, fiscalizando a vizinhança. & 1,72 \\
I) Não respondeu. & 1,72 \\
Total (9 idéias centrais) & 100,00
\end{tabular}

água limpa e doença, que colide com a representação social clássica, segundo a qual a doença tem a ver com "sujo" e saúde com "limpo"; notase ainda que a doença é vista como perigosa, mas quase não há qualquer menção ao risco eminente de uma epidemia; uma idéia equivocada ainda presente é a do lixo, em si, como criadouro da doença; há também alto desconhecimento da fase ovo do desenvolvimento do vetor;

b) fragmentado, com baixo grau de integração entre as partes: identifica-se que a dengue tem a ver com recipientes, água, mosquitos, larvas, ovos, vírus, lixo, trabalho integrado entre poder público e população, mas é fraca ou quase nula a consciência da adequada relação entre esses elementos.

As atitudes, por seu turno, revelam algum grau de descrença na participação popular, atribuída a uma tendência atávica desta população ao relaxamento.

Quanto aos comportamentos, revelam com freqüência aderência, muitas vezes externa, formal, "bem comportada" ("na minha casa eu faço as coisas direitinho, é tudo bem limpinho e organizado"), às recomendações ou diretivas emanadas do poder público.

Sugere-se, portanto, da parte dos poderes públicos, ações eficientes e eficazes de IEC, ou seja, é preciso Informar, Educar e Comunicar:

a) Informar: colocando a população permanentemente a par, com dados claramente compreensíveis, da evolução da doença no país, no estado e particularmente no local, para, mediante a informação, induzir a participação;

b) Educar: buscando, sobretudo, esclarecer a população sobre o relacionamento das partes do fenômeno dengue como enfermidade transmissível; c) Comunicar: buscando o relacionamento entre o ator técnico e o cidadão pelo estabelecimento do contato pela via do diálogo pedagógico interativo, com os uso de técnicas, instrumentos e linguagens adequadas para que a dengue possa fazer sentido não na teoria (lógica sanitária) nas no cotidiano (lógica do senso comum) da vida das populações vítimas reais e potenciais da doença, de um ponto de vista crítico.

Com efeito, como assinalam Vasconcelos \& Brito 17 (p. 149) analisando o pensamento de Paulo Freire, "é, na pedagogia crítica, o desafio a ser alcançado o de aceitar que o subjetivismo está mais presente e interage de forma intensa e equilibrada com o mundo objetivo. Trabalhar esse evento, levando os alunos (ou a população, grifo nosso) aproveitarem ao máximo sua capacidade pessoal para lidar com o realismo do cotidiano, parece ser uma maneira de prepará-lo para aceitar o que não pode ser mudado e para mudar o que o deve ser".

A importância de pesquisas do tipo da presente, que informem aos gestores o que pensa a população, aumenta as chances de que as ações a serem realizadas pelo poder público tenham maior precisão e impacto.

Recomenda-se, por isso, o uso do conteúdo dos DSC em mensagens que façam parte de um plano geral e descentralizado de IEC destinado a provocar mudanças na situação do controle da dengue/vetor no Município de São Sebastião. 


\section{Resumo}

Buscou-se, neste trabalho, identificar conhecimentos da população sobre a dengue e biologia do vetor, a fim de propiciar, através desse conhecimento, o diálogo entre a lógica técnica e a leiga, para conseguir avanços concretos na participação e no controle social da dengue e do vetor. Foi realizada pesquisa em área infestada pelo Aedes aegypti, com transmissão de dengue, no Município de São Sebastião, litoral norte do Estado de São Paulo, Brasil. Foram feitas cem entrevistas, com cinco questões abertas, abordando aspectos de interesse para o tema do controle da dengue e do vetor. Utilizou-se, para análise, a técnica do Discurso do Sujeito Coletivo (DSC). Os discursos revelam que a população não está conseguindo discriminar adequadamente o tipo ou modalidade de coleção de água mais apropriada para a criação do mosquito e que desconhece a fase de ovo no desenvolvimento do vetor. Observou-se consciência inadequada da relação de vários elementos da biologia do vetor, bem como da necessária integração entre poder público e a população. Sugere-se que as atividades educativas adotem resultados desta pesquisa como insumo, visando ao incremento da eficiência e eficácia social das ações participativas de combate ao dengue e controle do vetor.

Dengue; Promoção da Saúde; Controle de Vetores

\section{Referências}

1. Forattini OP. Ecologia, epidemiologia e sociedade. São Paulo: Artes Médicas/Edusp; 1992.

2. Chiaravalloti Neto F. Epidemiologia da dengue nas regiões de São José do Rio Preto e Araçatuba, São Paulo, 1990 a 1996 [Tese de Doutorado]. São Paulo: Universidade de São Paulo; 1999.

3. Lefèvre F, Lefèvre AM, Scandar SAS, Yassumaro S. Representações sociais sobre relações entre vasos de plantas e o vetor da dengue. Rev Saúde Pública 2004; 38:405-14.

4. Berger P, Luckmann T. Os fundamentos do conhecimento na vida cotidiana. In: Berger P, Luckmann T, organizadores. A construção social da realidade. Petrópolis: Editora Vozes; 1985. p. 35-68.

\section{Colaboradores}

G. R. A. M. Marques e L. L. N. Serpa participaram da redação do projeto de pesquisa, coleta dos dados em campo, digitação parcial dos dados de campo e interpretação dos resultados para redação final do artigo. A. F. Ribeiro participou da redação parcial do projeto de pesquisa, coleta dos dados em campo, digitação parcial dos dados de campo para digitação total em software específico de Discurso do Sujeiro Coletivo (DSC) interpretação dos resultados para redação final para publicação. A. M. C. Lefèvre e F. Lefèvre contribuíram para a elaboração do projeto de pesquisa, treinamento de pessoal na metodologia de DSC, a execução do projeto (coleta de dados, alimentação de dados no software, análise de dados, produção e interpretação de resultados) e redação do artigo.
5. Chiaravalloti Neto F, Moraes MS, Fernandes MA. Avaliação dos resultados de atividades de incentivo à participação da comunidade no controle da dengue em um bairro periférico no Município de São José do Rio Preto, São Paulo, e da relação entre conhecimento e práticas desta população. Cad Saúde Pública 1998; 14 Suppl 2:S101-9.

6. Chiaravalloti VB, Morais MS, Chiaravalloti Neto F, Conversani DT, Fiorin AM, Barbosa AAC, et al. Avaliação sobre a adesão às práticas preventivas do dengue: o caso de Catanduva, São Paulo, Brasil. Cad Saúde Pública 2002; 18:1321-9.

7. Lefèvre F, Lefèvre AMC. Promoção da saúde: a negação da negação. Rio de Janeiro: Vieira e Lent; 2005. 
8. Ribeiro AF, Marques GRAM, Voltolini JC, Condino LMF. Associação entre incidência de dengue e variáveis climáticas. Rev Saúde Pública 2006; 40:671-6.

9. Arduíno MB, Kita AT. Reciclagem de resíduos sólidos e criadouros de vetores de dengue em São Sebastião, litoral norte paulista. In: 1o Congresso Interamericano de Saúde Ambiental. Porto Alegre: Associação Interamericana de Engenharia Sanitária/Associação Brasileira de Engenharia Sanitária; 2004. p. 55.

10. Serviço Regional de Taubaté, Superintendência de Controle de Endemias, Secretaria da Saúde do Estado de São Paulo. Relatório técnico de Programa de Controle de Vetores de Dengue e Febre Amarela. Taubaté: Serviço Regional de Taubaté, Superintendência de Controle de Endemias, Secretaria da Saúde do Estado de São Paulo; 2004.

11. Superintendência de Controle de Endemias, Secretaria da Saúde do Estado de São Paulo. Manual de vigilância entomológica de Aedes aegypti. São Paulo: Superintendência de Controle de Endemias, Secretaria da Saúde do Estado de São Paulo; 1997.
12. Alexandre M. Representação social: uma genealogia do conceito. Comum 2004; 10:122-38.

13. Lefevre F, Lefevre AMC. O discurso do sujeito coletivo: um novo enfoque em pesquisa qualitativa (desdobramentos). Caxias do Sul: Educs; 2003.

14. Lefevre F, Lefevre AMC. Depoimentos e discursos: uma proposta de análise em pesquisa social. Brasília: Editora Líber Livro; 2005.

15. Souza-Santos R. Fatores relacionados à ocorrência de formas imaturas de Aedes aegypti na Ilha do Governador, Rio de Janeiro, Brasil. Rev Soc Bras Med Trop 1999; 32:373-82.

16. Moscovici S. Das representações coletivas às representações sociais. In: Jodelet D, organizador. As representações sociais. Rio de Janeiro: Eduerj; 2001. p. 45-66.

17. Vasconcelos MLMC, Brito RHP. Conceitos de educação em Paulo Freire. Petrópolis: Editora Vozes; 2006.

Recebido em 07/Mar/2006

Versão final reapresentada em 18/Dez/2006

Aprovado em 16/Jan/2007 